\title{
Deposição de filmes finos de nitreto de titânio em plasma com efeito de comprimento de catodo oco em gaiola catódica
}

\author{
Plasma deposition of titanium nitride thin films \\ under the effect of hollow cathode \\ length in cathodic cage
}

Sandro Santos da Silva ${ }^{1}$, Cintia de Laet Ravani Bottoni ${ }^{1}$, Leonardo Cabral Gontijo ${ }^{1}$,Sukarno Olavo Ferreira ${ }^{2}$

\footnotetext{
${ }^{1}$ Laboratório de Plasma - LabPlasma -PROPEMM/IFES, cep: 29040-780,Vitória, ES

e-mail: sandrosantosdasilva@gmail.com; cintia_ravani@hotmail.com; pleooog@gmail.com

${ }^{2}$ Centro de Ciências Exatas e Tecnológicas, Departamento de Física, 36571-000, Viçosa - MG

e-mail: sukarno.o.ferreira@gmail.com
}

\section{RESUMO}

A utilização de gaiola catódica se apresenta com um grande potencial de deposição de filmes finos e espessos, seja em substrato de vidro ou em peças metálicas. São inúmeras as possibilidades dessa técnica. Neste trabalho, a descarga de plasma em gaiola catódica foi usada para deposição de filmes de nitreto de titânio em substrato de vidro. O objetivo foi o de comparar as propriedades dos filmes depositados com uso de duas gaiolas com tampas de espessuras diferentes. Para caracterização dos filmes foram feitas análises por difração de raios X, medidas de espessura por reflectometria, medidas de resistividade elétrica, transmitância e imagens das superfícies por microscopia eletrônica de varredura e análise da composição por EDS. A reflectometria mostrou que a taxa de deposição e a rugosidade dos filmes aumentaram com a utilização de tampa de maior espessura $(10 \mathrm{~mm})$. O filme depositado na atmosfera de $155 \mathrm{sccm}$ de $\mathrm{N}_{2}, 95 \mathrm{sccm}$ de $\mathrm{H}_{2}$ e pressão de 0,5 Torr apresentou baixa transmitância na região do vermelho e infravermelho próximo, tornando-o um candidato para ser utilizado como filtro de infravermelho.

Palavras chaves: Gaiola catódica, nitreto de titânio, filmes finos.

\section{ABSTRACT}

The use of cathodic cage contributes for thin and thick films deposition on glass substrate or over metal substrates. There are many possibilities in using this technique. Into this work, the discharge of plasma on cathodic cage was used for titanium nitrite films deposition on glass substrate. The aim was to compare the films properties with use of two different thicknesses of cover cages. The films characterization were made using X-Ray diffraction analysis, thickness measurements by reflectometry, electrical resistivity measurements, transmittance and images of surfaces by scanning electron microscopy and analysis of composition by EDS. Reflectometry analysis had showed that deposition rate and surface films roughness had increased with use of a thicker cover cage (10 mm of thickness). The film deposited in the atmosphere containing $155 \mathrm{sccm}$ of $\mathrm{N}_{2}, 95 \mathrm{sccm}$ of $\mathrm{H}_{2}$ and pressure of 0.5 Torr had showed low transmittance in the region of the red and near infrared, indicating the use as IR filter.

Keywords: cathodic cage, titanium nitride, thin films.

\section{INTRODUÇÃO}

Os avanços tecnológicos, nos diferentes campos de pesquisa, têm buscado melhorar as técnicas já conhecidas e promover o desenvolvimento de novas na busca de matérias com custos menores e de aplicações mais abrangentes, como a capacidade de deposição em grandes áreas que são altamente desejáveis. A gaiola catódica, por ser um processo que se utiliza do reator do sistema de nitretação, se apresenta com um grande potencial de deposição de filmes finos e espessos, seja em substrato de vidro ou em peças metálicas. São inúme- 
ras as possibilidades dessa técnica, entretanto, neste trabalho, a descarga a plasma em gaiola catódica foi usada para deposição de filmes de nitreto de titânio em substrato de vidro.

Nessa técnica, o plasma atua na gaiola catódica e arranca material, principalmente, das paredes dos furos, que reage com gases do plasma, neste caso o nitrogênio, e se depositam sobre o substrato de vidro posicionado no interior da gaiola em potencial suspenso. Nos furos das paredes da gaiola acontecem descargas de catodo oco que produzem maiores densidades de íons do que as descargas convencionais, pois a densidade do plasma dentro dos furos é muito maior, por isso uma quantidade elevada de íons é ejetada das paredes dos furos. Segundo Koch et al [1], o máximo espalhamento ocorre quando o produto pressão $\mathrm{x}$ tamanho da cavidade varia aproximadamente entre 0,375 e $3,75 \mathrm{~cm}$. Torr.

Esse trabalho tem como objetivo a utilização dessa técnica na deposição de filmes de nitreto de titânio que é um dos vários nitretos de metal de transição que desperta grande interesse industrial devido a sua alta dureza, alto ponto de fusão, boa resistência ao desgaste e à corrosão [2]. Por essas características ele é muito usado como cobertura para ferramentas de corte [3] como fresas e brocas que adquirem alta dureza e baixo desgaste por atrito fazendo com que tenham maior vida útil e bom desempenho de corte. É um material que, por sua biocompatibilidade, pode ser usado como revestimentos em implantes dentários, reduzindo a proliferação e a adesão bacteriana [4]. Apresenta bons resultados quando usados como cobertura de eletrodos de titânio para uso em marcapasso [5]. O nitreto de titânio também possui alta reflexão no infravermelho podendo ser usado para filmes seletivamente transparentes como "espelhos de calor" em revestimentos de janelas $[6,7]$.

\section{MATERIAIS E MÉTODOS}

Como substrato foram usadas lâminas de vidro borossilicato de $1 \mathrm{~mm}$ de espessura e cortados com dimensões $25 \mathrm{~mm}$ e10 mm. A limpeza dos substratos foi feita com detergente, água, banho de ultrassom por 1 minuto e secador. Após a secagem, os substratos eram colocados no interior da gaiola. O equipamento utilizado para deposição dos filmes foi o reator de nitretação a plasma pulsado modelo Thor NP 5000 SDS.

Uma das gaiolas catódicas utilizadas nessa pesquisa é mostrada na Figura 1 sob efeito do plasma. Ela é de titânio comercialmente puro, grau II, com $100 \mathrm{~mm}$ de diâmetro externo.

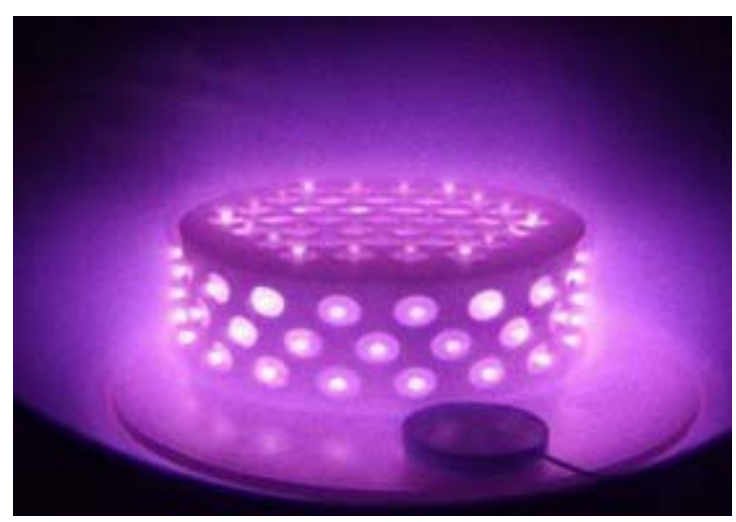

Figura 1: Gaiola catódica de titânio de diâmetro $100 \mathrm{~mm}$ com tampa de $1 \mathrm{~mm}$ de espessura.

A lateral das gaiolas tinha $45 \mathrm{~mm}$ de altura com 3 fileiras de furos. A segunda gaiola tinha a tampa com espessura de $10 \mathrm{~mm}$. As tampas tinham 37 furos de $9 \mathrm{~mm}$ de diâmetro equidistantes de $12,9 \mathrm{~mm}$ (distância entre os centros dos furos). A distância dos substratos à tampa era mantida em $12 \mathrm{~mm}$ utilizando-se um suporte de aço de $30 \mathrm{~mm}$ de diâmetro apoiado sobre uma folha de mica circular de $95 \mathrm{~mm}$ de diâmetro. Sobre o cilindro era colocado uma segunda folha de mica com $70 \mathrm{~mm}$ de diâmetro sobre a qual eram colocados os substratos. A gaiola catódica ficou apoiada diretamente no catodo do equipamento, mas na parte interna da gaiola foi usada uma folha de mica para assegurar melhor uniformidade do filme. Deposições sem a mica geraram filmes não uniformes e com defeitos aparentes a olho nu. A folha de mica também garantia que o suporte e as amostras ficassem em potencial suspenso. 


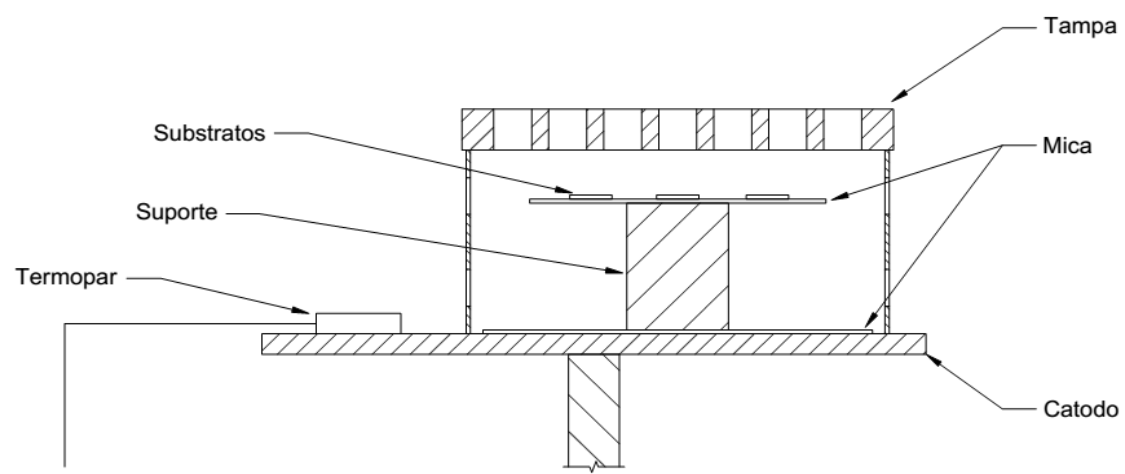

Figura 2: Corte da gaiola mostrando o seu interior com o suporte e o posicionamento dos substratos de vidro.

Foram estudados os efeitos da variação da espessura da tampa da gaiola catódica nas propriedades dos filmes depositados. Para tanto foram feitas 11 deposições com cada uma das gaiolas, com tampas de espessuras de $1 \mathrm{~mm}$ e $10 \mathrm{~mm}$. Em cada ensaio, três substratos eram colocados sobre a folha de mica conforme mostrado na figura 2. O filme depositado no substrato central era utilizado para fazer as medidas posteriores. Os dois filmes depositados nos substratos laterais eram utilizados para auxiliar na verificação da uniformidade da deposição. A bomba de vácuo era acionada e a pressão reduzida para 1 Torr quando então era introduzido hidrogênio na câmara do reator com fluxo de $250 \mathrm{sccm}$. O reator era acionado e então o plasma se formava sobre o catodo com a gaiola. $\mathrm{O}$ aquecimento do sistema era feito pelo próprio plasma com a utilização de hidrogênio nos primeiros 30 minutos em pressão de 1,0 Torr e fluxo de $250 \mathrm{sccm}$. Depois desse tempo era introduzido nitrogênio. Nesse momento, os fluxos de entrada dos dois gases na câmara do reator eram ajustados conforme mostra a tabela 1 . Quando a temperatura atingia $300{ }^{\circ} \mathrm{C}$, o plasma era mantido atuando na gaiola por mais 1 hora. Após esse período, o plasma era desligado. Foram selecionados os filmes dos ensaios que apresentaram deposição mais uniforme por toda a superfície dos 3 substratos.

Tabela 1: Parâmetros utilizados na deposição usados com as duas gaiolas de tampas com espessuras de $1 \mathrm{~mm}$ e $10 \mathrm{~mm}$ à temperatura de $300^{\circ} \mathrm{C}$.

\begin{tabular}{l|l|l|l|l}
\hline Ensaio & $\begin{array}{l}\text { Fluxo de } \\
\mathrm{H}_{2}(\mathrm{sccm}(\%))\end{array}$ & $\begin{array}{l}\text { Fluxo de } \\
\mathrm{N}_{2}(\mathrm{sccm}(\%))\end{array}$ & $\begin{array}{l}\text { Pressão } \\
(\text { Torr })\end{array}$ & $\begin{array}{l}\text { Pressão x diâmetro } \\
\text { do furo (cm.Torr) }\end{array}$ \\
\hline 1 & $162(64 \%)$ & $88(36 \%)$ & 1,0 & 0,90 \\
\hline 2 & $28(11 \%)$ & $222(89 \%)$ & 1,0 & 0,90 \\
\hline 7 & $95(38 \%)$ & $155(62 \%)$ & 0,5 & 0,45 \\
\hline
\end{tabular}

A difração de raios X (DRX) foi feita no Laboratório do Propem/Ifes/Vitória utilizando-se o difratômetro da marca Bruker, modelo D2 Phaser, radiação $\mathrm{Cu}-\mathrm{k} \alpha(\lambda=0,1542 \mathrm{~nm})$, a $30 \mathrm{kV}$ e $10 \mathrm{~mA}$. A varredura $\left(2 \theta\right.$ de 20 a $80^{\circ}$ ) foi feita com passo de $0,01 \circ$ por segundo. A reflectometria de raios $\mathrm{x}$ (RRX) foi realizada para determinar a espessura, rugosidade e densidade dos filmes. Para tanto, foi utilizado o difratômetro de Raios X Bruker D8 Discover pertencente ao departamento de Física da Universidade Federal de Viçosa, utilizando, também, radiação $\mathrm{Cu} \mathrm{K \alpha}$ e passo de $0,002^{\circ}, 1 \mathrm{~s}$ por passo, $40 \mathrm{KV} / 30 \mathrm{~mA}$. As propriedades elétricas (resistividade, mobilidade e número de portadores de carga) foram medidas à temperatura ambiente por um aparelho de Efeito Hall, marca Ecopia, modelo HMS - 3000 com campo magnético de 0,556 T pertencente ao Laboratório de Superfície e Filmes Finos Propemm/Ifes/Vitória. Foi usado o método de quatro pontas, amostras quadradas e distância de $1 \mathrm{~cm}$ entre as pontas. As curvas de transmitância dos filmes foram determinadas utilizando-se o espectrofotômetro Cary 1E da marca Variant pertencente ao laboratório de Química da UFES. As varreduras foram feitas com comprimentos de onda na faixa de $300 \mathrm{~nm}$ a $1000 \mathrm{~nm}$. O vidro borossilicato foi usado como branco. Para a caracterização dos filmes e suas composições foram utilizadas microscopia eletrônica de varredura e sistema de energia dispersiva (MEV e EDS), marca ZEISS modelo EVO MA10, pertencente ao Propemm/IFES. Além disso, as imagens e as análises foram usadas para comparar, constatar e quantificar presença de titânio e nitrogênio nos filmes depositados. 


\section{RESULTADOS E DISCUSSÃO}

Filmes de nitreto de titânio foram depositados por pulverização catódica com uso de gaiola catódica. Para a deposição foram utilizados substratos de vidro dispostos como mostrado na Figura 2.

Os pares de filmes obtidos são mostrados na Figura 3 onde é possível observar a tonalidade adquirida por cada um deles. De cada par mostrado, o filme da esquerda é o depositado com a gaiola de tampa mais fina.

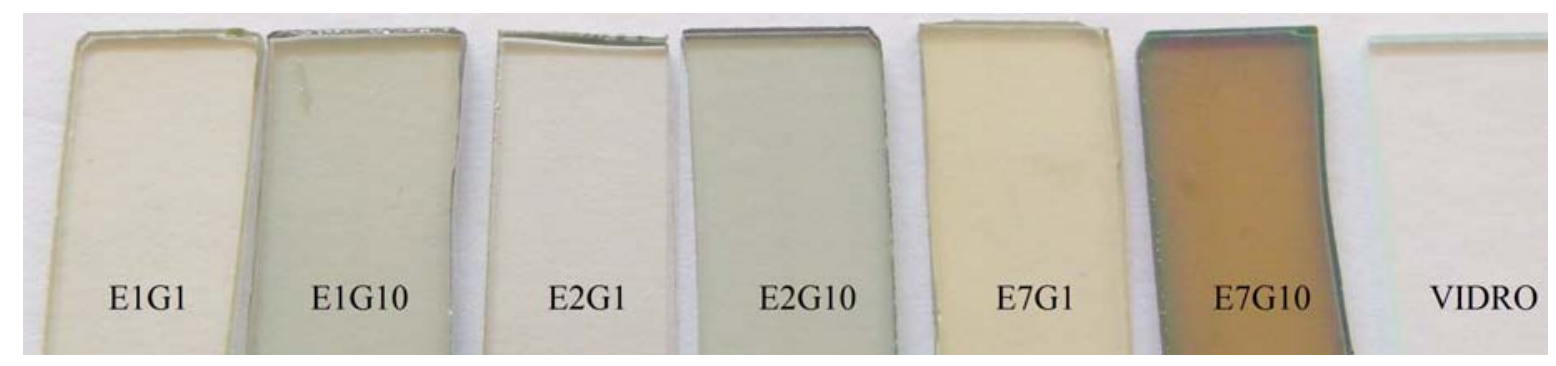

Figura 3: Fotografia dos pares de filmes obtidos sobre substrato de vidro. Os nomes E1, E2 e E7 se referem aos ensaios e os nomes G1 e G10 correspondem ao uso da gaiola com tampa de $1 \mathrm{~mm}$ e tampa de $10 \mathrm{~mm}$ respectivamente. À direita da figura é mostrada uma lâmina de vidro sem filme depositado.

\subsection{Difratogramas de raios $x$}

Na Figura 4 observamos os difratogramas de Raios X dos três pares de filmes. Os difratogramas são típicos de filmes amorfos não apresentando nenhum pico. As condições de deposição favoreceram o crescimento de filmes amorfos. Provavelmente devido ao pequeno tempo de deposição, apenas 1 hora. Também contribuem para formação de filmes amorfos a baixa temperatura de deposição $\left(300^{\circ} \mathrm{C}\right)$ e taxa de deposição relativamente alta [2]. Outro fator que pode contribuir é a proximidade do substrato à tampa fazendo com que partículas com energia relativamente elevada, vindas diretamente do furo, atinjam a superfície do substrato durante a deposição do filme.

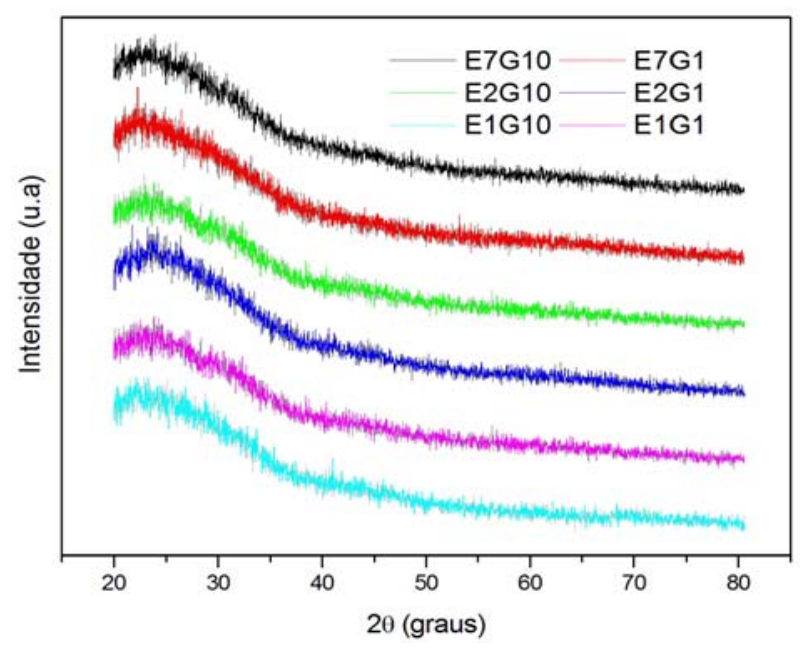

Figura 4: Difratogramas dos filmes finos as amostras E1G1, E1G10, E7G1 e E7G10.

Natália Daudt e colaboradores [8], usando gaiola catódica de titânio para deposição de filmes de nitreto de titânio obteve filmes com alta cristalinidade. As condições de deposição eram diferentes das usadas neste trabalho, pois utilizaram atmosfera de Ar- $\mathrm{N}_{2}-\mathrm{H}_{2}$, as gaiolas tinham geometria diferente, menor e com menos furos, temperatura da deposição era de $450^{\circ} \mathrm{C}$, pressão de 0,75 Torr, tempo de deposição de duas horas e os substratos ficavam mais afastados dos furos da gaiola. Os fatores que devem ter contribuído para obtenção de filmes cristalinos no trabalho de Natália Daudt [8] foram o uso da temperatura mais alta $\left(450^{\circ} \mathrm{C}\right)$, tempo de deposição maior $(2 \mathrm{~h})$ e maior distância do substrato à tampa da gaiola.

Yasdani e colaboradores [9] depositaram filmes de nitreto de titânio sobre aço ferramenta H11 utilizando plasma e gaiola catódica e também obtiveram filmes cristalinos utilizando tempos de deposição de 5, 7,5 e 10 horas e temperatura de tratamento a $500{ }^{\circ} \mathrm{C}$. 


\subsection{Reflectogramas}

Os reflectogramas dos filmes são mostrados na Figura 5. As curvas obtidas a partir da reflectometria são apresentas com cor preta. As curvas teóricas são as de cor vermelha. Para ajustes das curvas teóricas usando o software Wingixa da Philips foram testados dois modelos. O primeiro modelo foi de um filme de uma única camada sobre o substrato e o segundo modelo, um filme composto de duas camadas, a primeira camada superficial mais fina e uma segunda camada mais espessa sobre o substrato. A densidade do vidro, no ajuste, foi mantida fixa em $2,2 \mathrm{~g} / \mathrm{cm}^{3}$. As demais variáveis foram deixadas livres. Dos dois modelos, os melhores ajustes foram obtidos usando o modelo de duas camadas e os resultados dos ajustes são mostrados na Tabela 2. A segunda camada possivelmente pode ser resultado da oxidação superficial do filme de TiN ocasionando (produzindo) uma camada superficial, possivelmente de TiON.

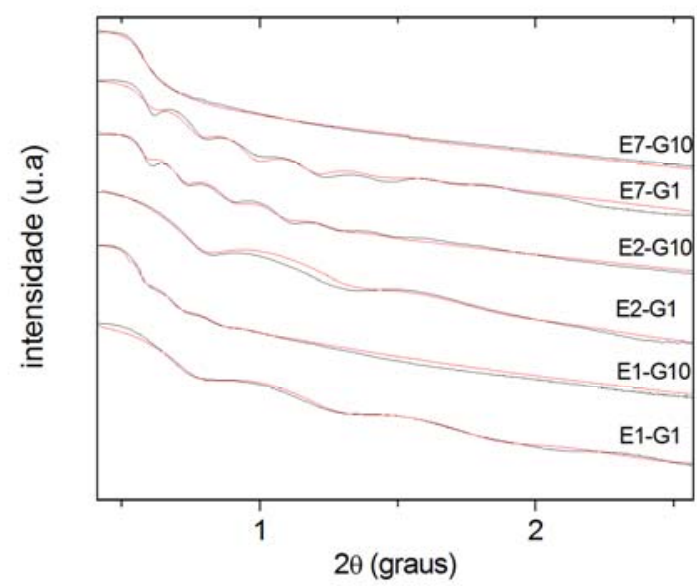

Figura 5: Reflectogramas dos filmes mostrando franjas de interferência. As curvas pretas foram obtidas experimentalmente e as vermelhas são as curvas teóricas obtidas através do software Wingixa.

Observa-se que independente dos fluxos utilizados (ver tabela 1), uma maior espessura da tampa produz um aumento nas espessuras dos filmes e, consequentemente, numa maior rugosidade superficial dos filmes, pois quanto maior a taxa de deposição maior a rugosidade. Além disso, partículas com energia mais alta, produzidas nas regiões de plasma mais denso na tampa de parede mais espessa, também podem contribuir para uma maior rugosidade destes filmes.

Tabela 2: Parâmetros de ajuste das curvas teóricas às curvas experimentais de RRX.

\begin{tabular}{l|l|l|l|l|l|l|l|l|l|l}
\hline \multirow{2}{*}{ Amostra } & \multicolumn{3}{|c|}{ Espessura $(\mathrm{nm})$} & \multicolumn{3}{c|}{ Rugosidade $(\mathrm{nm})$} & \multicolumn{3}{c|}{ Densidade $\left(\mathrm{g} / \mathrm{cm}^{3}\right)$} & \multicolumn{2}{c}{$\chi^{2}$} \\
\cline { 2 - 11 } & TiN & TiON & Total & vidro & TiN & TiON & vidro & TiN & TiON & \\
\hline E1G1 & 13,4 & 2,3 & 15,7 & 2,0 & 2,5 & 0,8 & 2,2 & 3,8 & 2,9 & 0,08 \\
E1G10 & 35,9 & 2,6 & 38,5 & 2,0 & 4,7 & 0,7 & 2,2 & 3,7 & 1,3 & 0,08 \\
E2G1 & 12,8 & 2,2 & 15,0 & 2,0 & 1,6 & 0,9 & 2,2 & 3,7 & 2,9 & 0,06 \\
E2G10 & 36,9 & 3,2 & 40,1 & 2,1 & 2,3 & 0,6 & 2,2 & 3,6 & 1,4 & 0,03 \\
E7G1 & 28,2 & 3,3 & 31,5 & 1,9 & 1,8 & 0,7 & 2,2 & 4,1 & 3,1 & 0,06 \\
E7G10 & 122,0 & 3,0 & 125,0 & 2,0 & 4,8 & 0,5 & 2,2 & 5,0 & 1,4 & 0,09 \\
\hline
\end{tabular}


Tabela 3: Razão entre as taxas de deposição para cada par de filme depositado com gaiolas de espessuras diferentes.

\begin{tabular}{l|l|l|l}
\hline Ensaio & Fluxo de $\mathrm{N}_{2}(\%)$ & Fluxo de $\mathrm{H}_{2}(\%)$ & Razão \\
\hline 1 & 36 & 64 & 2,7 \\
2 & 89 & 11 & 2,9 \\
7 & 62 & 38 & 4,3 \\
\hline
\end{tabular}

Observa-se ainda que, para uma mesma pressão, utilizadas na deposição dos pares de filmes E1 e E2, o aumento da presença de nitrogênio na composição do gás não é traduzido em um aumento significativo na taxa de deposição de TiN pois as espessuras obtidas foram muito próximas. A taxa de deposição é praticamente a mesma. Novamente, o bombardeamento da superfície do filme por partículas de alta energia mais pesadas, produzidas pelo plasma mais denso, provoca um efeito de pulverização do filme, reduzindo a taxa de crescimento. Podemos dizer que existe uma competição entre a deposição dos filmes no substrato e a sua pulverização. Para o par de filmes E7, a espessura foi maior quando comparada com os outros dois pares, E1 e E2. Além da proporção de $\mathrm{H}_{2}$ e $\mathrm{N}_{2}$ utilizada, a redução da pressão total provavelmente aumentou o efeito de catodo oco no furo, pois o brilho nos furos da gaiola era mais intenso, indicando maior pulverização e produção de íons, resultando numa maior taxa de deposição como pode ser visto na tabela 2 , no resultado das espessuras do par de filmes E7. Além disso, na tabela 3 pode ser vista a razão entre as taxas de deposição dos pares de filme, ou seja, o quanto a taxa de deposição do filme crescido utilizando-se a gaiola G10 foi maior do que a taxa de deposição utilizando-se a gaiola G1. Podemos ver que o maior aumento na taxa de deposição foi também para o ensaio em que se usou a pressão menor de 0,5 Torr.

Yasdani e colaboradores [9] obtiveram filmes de nitreto de titânio com espessuras entre 311 a 3121 nm utilizando tempos de deposição de 5, 7,5 e 10 h e três composições de gases nas razões de H2/N2 iguais a 0,33, 1 e 3. A maior taxa de deposição ocorreu quando a razão H2/N2 foi igual 1.

Dauldt e colaboradores [10] depositaram filmes de nitreto de titânio com a mesma técnica e obtiveram filmes cristalinos com espessuras de $250 \mathrm{~nm}$ e $600 \mathrm{~nm}$. A diferença das duas espessuras obtidas no trabalho de Daudt tem relação com o número de furos utilizados nas gaiolas. Uma com 9 furos e outra com 17 furos. A maior espessura dos filmes obtidos por Daudt quando comparados aos filmes obtidos neste trabalho se deve a utilização, além do nitrogênio e hidrogênio, do argônio, que por ter massa atômica muito mais próxima dos átomos do alvo (quando comparado com o nitrogênio) oferecem maior poder de "sputtering". Além disso, o tempo de deposição utilizado foi o dobro do utilizado nesse trabalho.

\subsection{Transmitância}

Na Figura 6 são mostradas as curvas de transmitância para os seis filmes estudados. O filme E7G10 apresentou menor transmitância e isso se deve provavelmente a sua maior espessura.

Além disso, esse filme apresenta uma queda mais acentuada na transmitância na região do vermelho que não ocorreu com os demais. Isso pode ser um indicativo que esse filme seja o que tenha se aproximado mais do nitreto de titânio estequiométrico já que este tem baixa transmitância no infravermelho [6,7]. 


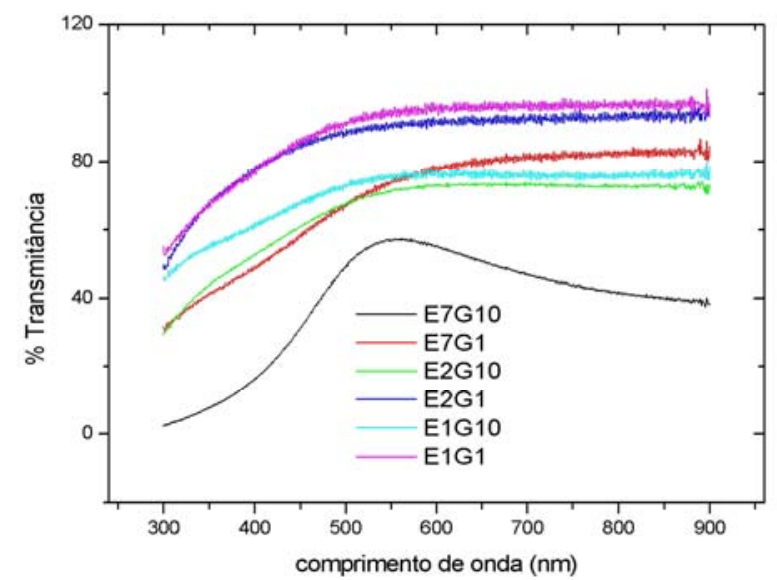

Figura 6: Transmitância dos filmes depositados sobre substrato de vidro.

Um filme com essa característica pode ser depositado em vidros para uso em janelas de construções residenciais ou comerciais em clima frio, pois podem reduzir a quantidade de calor transferida por radiação que é refletida no vidro, diminuindo a transferência de calor para o exterior. Também pode ser utilizado em placas de aquecimento térmico de água, aumentando o rendimento do aquecedor [7].

\subsection{Resistividade elétrica dos filmes}

A Tabela 4 mostra os valores da resistividade, mobilidade e o número de portadores de carga para as seis amostras estudadas. A amostra E7G10 foi o que apresentou menor resistividade, maiores mobilidade e número de portadores de carga. Essa variação na resistividade deve estar associada a quantidade de nitrogênio no filme. Segundo Vasu [8] filmes de nitreto de titânio podem apresentar grãos condutores quando a composição do filme é estequiométrica (TiN) e grãos resistivos quando composição é subestequiométrica.

Tabela 4: Resistividade, mobilidade e o número de portadores de carga.

\begin{tabular}{l|l|l|l}
\hline \multicolumn{1}{c|}{ AMOSTRA } & \multicolumn{1}{|c|}{$\begin{array}{c}\text { RESISTIVIDADE } \\
\text { E1G1 }\end{array}$} & $\begin{array}{c}\text { MOBILIDADE } \\
\mathrm{cm}^{2} / \mathrm{Vs}\end{array}$ & $\begin{array}{c}\text { No DE PORTADO- } \\
\text { RES DE CARGA } \\
10^{12} / \mathrm{cm}^{3}\end{array}$ \\
\hline E1G10 & $1,1.10^{4}$ & $1,2 \cdot 10^{1}$ & $4,8 \cdot 10^{1}$ \\
\hline E2G1 & $4,4 \cdot 10^{3}$ & $6,7.10^{1}$ & $5,0.10^{0}$ \\
\hline E2G10 & $2,2 \cdot 10^{3}$ & $1,2 \cdot 10^{2}$ & $4,0.10^{1}$ \\
\hline E7G1 & $3,1.10^{3}$ & $1,4 \cdot 10^{1}$ & $1,4 \cdot 10^{2}$ \\
\hline E7G10 & $7,7 \cdot 10^{3}$ & $8,0.10^{0}$ & $5,4 \cdot 10^{2}$ \\
\hline & $3,0.10^{-1}$ & $1,7 \cdot 10^{3}$ & $3,1 \cdot 10^{4}$ \\
\hline
\end{tabular}

Os valores encontrados para a resistividade, com exceção para as dos filmes E7G10 e E1G1, têm mesma ordem de grandeza dos valores encontrados por Tarniowy e colaboradores [2] para as resistividades de filmes finos de nitreto de titânio amorfos, entre $10^{2}$ a $10^{3} \Omega . \mathrm{cm}$. A medida de resistividade do filme E7G10 ficou bem menor que a dos demais filmes mas também muito maior do que a encontrada por Tarniowy para filmes cristalinos que foi dentro da faixa de 25 a $100\left(.10^{-6}\right) \Omega . \mathrm{cm}$. 


\subsection{MEV e EDS}

Na Figura 7 temos a imagem da borda do filme E7-G10 onde pode ser visto o filme, a região à direita e a esquerda a borda do filme fraturada e sem o filme. Nessa mesma figura está indicada uma região colorida onde foi feito a análise por EDS.

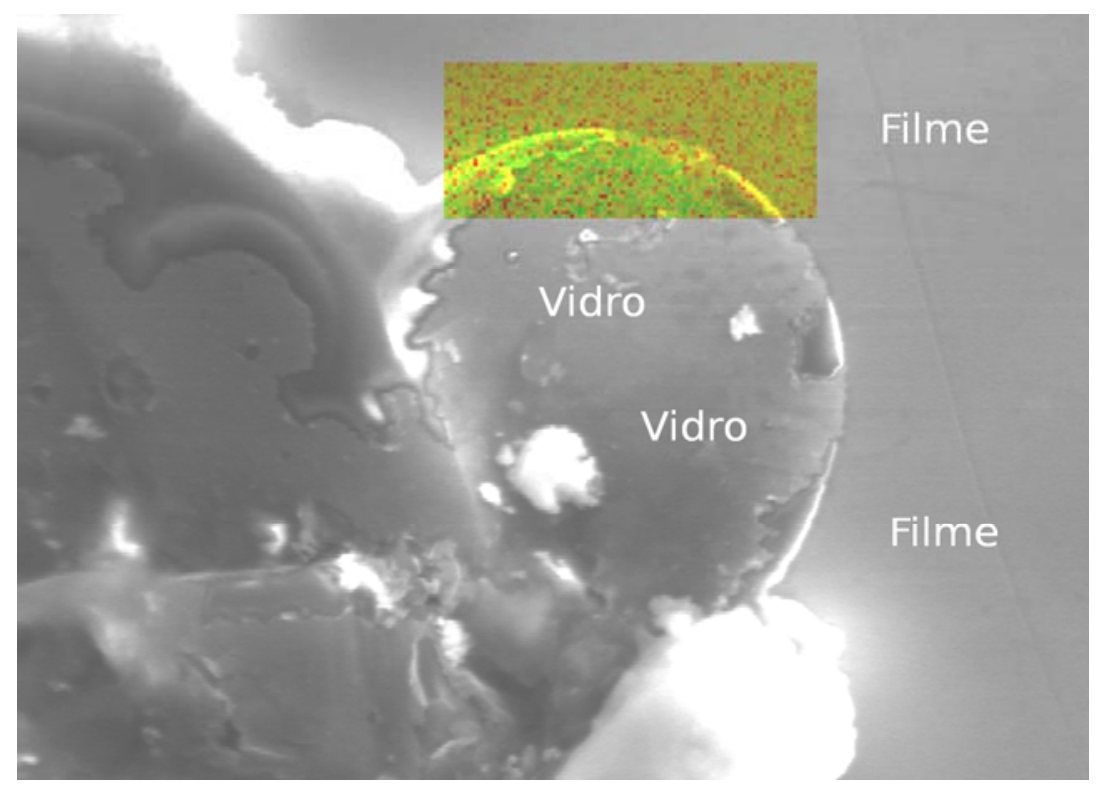

Figura 7: Imagem obtida por MEV de uma fratura em forma de semicírculo na borda do substrato da amostra E7-G10.

Nas Figuras 8 e 9 é mostrado o mapeamento da superfície próxima a borda do filme onde se verifica a presença de titânio e nitrogênio na região onde se tem o filme depositado. A varredura feita pelo EDS da superfície de cada filme em uma região central quadrada de lado $100 \mu \mathrm{m}$ identificou os elementos presentes no substrato/filme e suas respectivas quantidades em percentual de peso. Esses dados estão na tabela 5. Observando a coluna do elemento titânio pode-se notar uma maior quantidade nos filmes que foram depositados utilizando-se a gaiola com tampa de espessura de $10 \mathrm{~mm}$, como já tinha sido constatado pelos dados de reflectometria.

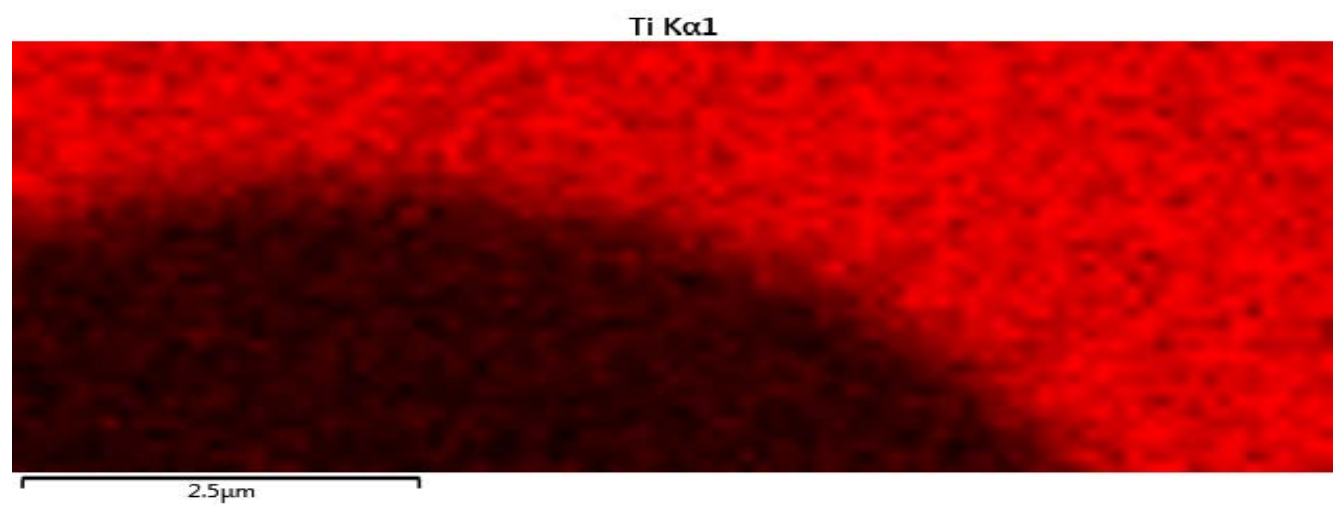

Figura 8: Mapeamento obtido por EDS indicando a presença de titânio no filme, a região indicada pela cor vermelha. 


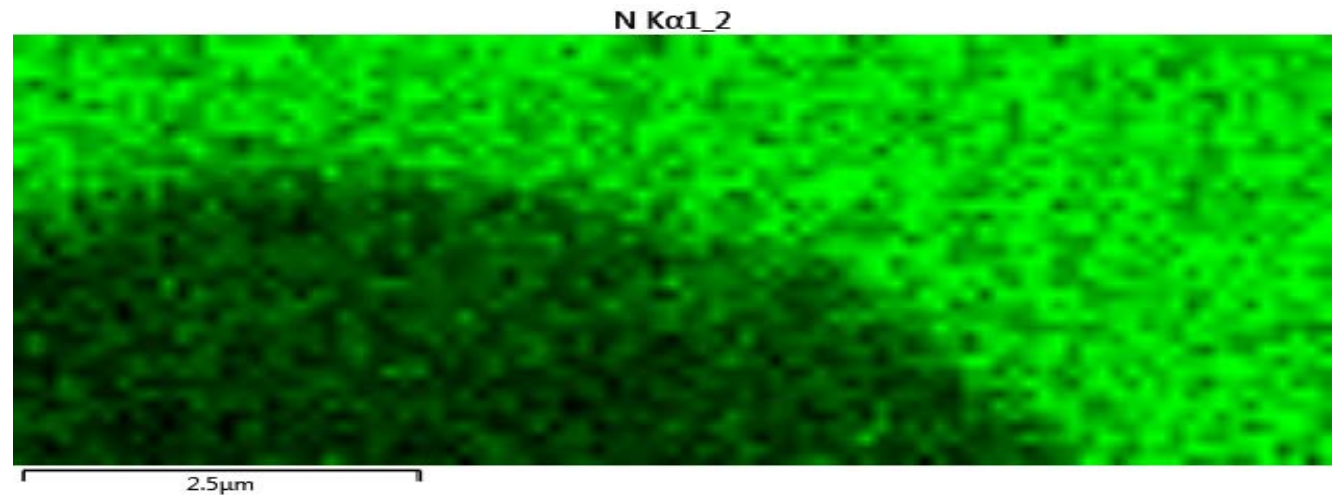

Figura 9: Mapeamento obtido por EDS indicando a presença de nitrogênio no filme, a região verde.

Os resultados para os filmes E2 e E1 foram iguais, sendo 0,8 quando usada gaiola G10 e 0,3 quando usada a gaiola G1. Ou seja, por essa medida o aumento na quantidade de titânio no filme quando se usa a gaiola G10 e pressão 1,0 Torr, foi o mesmo, independente das duas concentrações de gases utilizada. Já quando se utilizou uma pressão menor de 0,5 Torr e uma concentração de gás intermediária, o aumento da quantidade de titânio depositado foi muito maior quando se usou a gaiola G10.

Tabela 5: Percentual em peso dos elementos contidos no filme/substrato

\begin{tabular}{l|c|c|c|c|c|c|c|c|c|c}
\hline \multicolumn{10}{c}{ ELEMENTOS } \\
\hline AMOSTRA & $\mathrm{O}$ & $\mathrm{Si}$ & $\mathrm{Na}$ & $\mathrm{Ca}$ & $\mathrm{Mg}$ & $\mathrm{Al}$ & $\mathrm{Ti}$ & $\mathrm{N}$ & $\mathrm{K}$ & total \\
\hline E1G1 & 52,4 & 31,4 & 9,4 & 3,5 & 2,2 & 0,7 & 0,3 & 0,0 & 0,0 & 99,9 \\
E1G10 & 52,0 & 31,9 & 8,1 & 3,4 & 1,9 & 1,1 & 0,8 & 1,1 & 0,2 & 100,5 \\
E2G1 & 52,4 & 31,0 & 9,6 & 3,6 & 2,2 & 0,6 & 0,3 & 0,3 & 0,0 & 100 \\
E2G10 & 51,6 & 31,8 & 9,2 & 3,7 & 2,3 & 0,0 & 0,8 & 0,4 & 0,0 & 99,8 \\
E7G1 & 50,7 & 30,9 & 9,7 & 3,8 & 2,1 & 0,6 & 0,7 & 0,3 & 0,2 & 99 \\
E7G10 & 43,9 & 32,5 & 8,7 & 3,9 & 2,1 & 0,6 & 3,0 & 5,1 & 0,0 & 99,8 \\
\hline
\end{tabular}

As Figuras 10 a 12 mostram imagens obtidas por MEV das superfícies dos filmes produzidos com a gaiola G10 com um aumento de 1500X. Na Figura 10, que mostra uma região da superfície do filme E7G10, é possível observar algumas cavidades. Na Figura 11 podemos ver a imagem da superfície do filme E2G10 onde praticamente não se observam essas cavidades. É o filme produzido com maior quantidade de nitrogênio. 


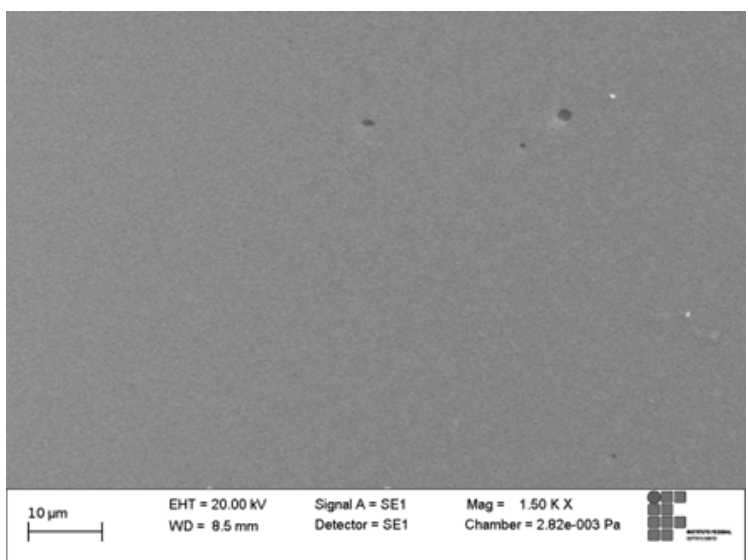

Figura 10: Imagem obtida por MEV com uma ampliação de 1500X de uma região da superfície do filme E7G10. Alguns poros ou furos podem ser observados.

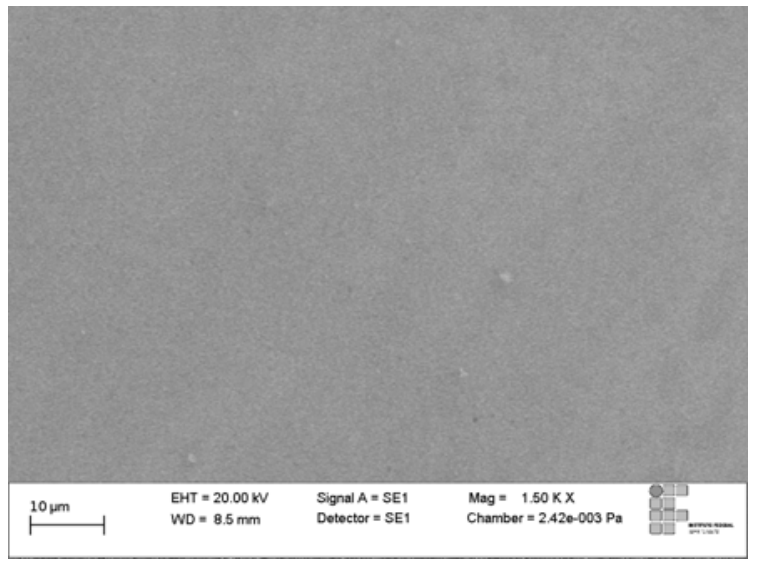

Figura 11: Imagem obtida por MEV com uma ampliação de 1500X de uma região da superfície do filme E2G10

A Figura 12 apresenta a superfície do filme E1G10 produzido a partir de um plasma rico em hidrogênio onde podem ser observados uma grande quantidade de furos, poros (ou cavidades) que não foram observados nos demais.

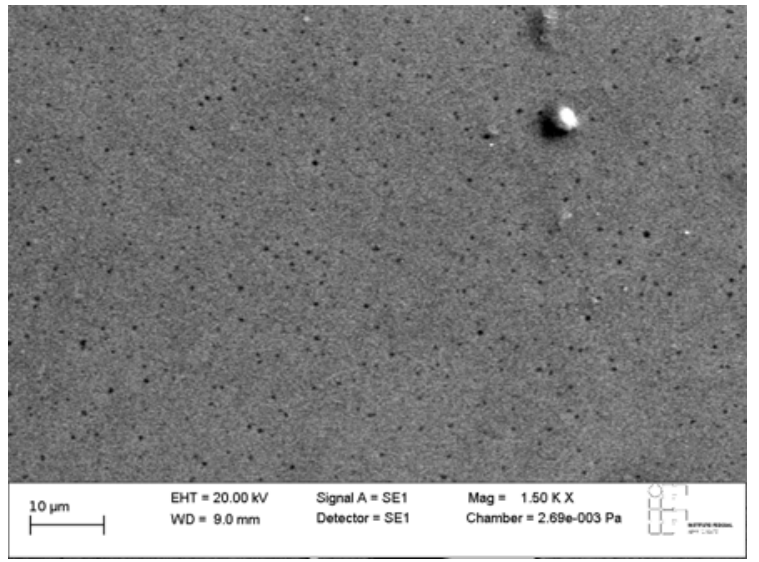

Figura 12: Imagem obtida por MEV com uma ampliação de 1500X de uma região da superfície do filme E1G10 apresentando uma grande quantidade de poros

De acordo com Natália Daudt e colaboradores [11], a introdução de hidrogênio modifica a quantidade de espécies ativas no plasma modificando as características no filme depositado. No trabalho de Daudt, a introdução de pequenas quantidades de hidrogênio aumentou a taxa de deposição dos filmes e também gerou 
filmes mais homogêneos. Já neste trabalho, foi usado um fluxo relativamente alto de hidrogênio no ensaio E1. Isso afetou a taxa de deposição para menos quando comparado com o ensaio E2, com fluxo menor de hidrogênio. Além disso, a introdução de um fluxo muito elevado de hidrogênio de alguma forma pode ter contribuido na formação de poros no filme E1G10, como pode ser observado na figura 12.

\section{CONCLUSÕES}

Utilizando técnica de deposição por plasma com gaiola catódica de titânio e atmosfera de hidrogênio e nitrogênio foi possível produzir filmes finos sobre substrato de vidro com diversas taxas de deposição, cores, espessuras, rugosidades e resistividade elétricas distintas. As condições de deposição, baixos tempo e temperatura de deposição favoreceram o crescimento de filmes amorfos. Foram depositados filmes usando-se duas gaiolas com tampas de espessuras diferentes e misturas diferentes dos gases hidrogênio e nitrogênio. A utilização da tampa de $10 \mathrm{~mm}$ de espessura aumenta a taxa de deposição e a rugosidade dos filmes quando comparado com os filmes depositados com a gaiola de tampa de $1 \mathrm{~mm}$ de espessura. A rugosidade na superfície dos filmes depositados com a tampa de $10 \mathrm{~mm}$ de espessura foi cerca de 3 vezes maior do que a rugosidade dos filmes depositados com a tampa mais fina. Um dos filmes depositados, o E7-G10, apresentou baixa transmitância na região do infravermelho próximo. A resistividade dos filmes em geral se apresentou muito elevada o que era esperado para filmes de nitreto de titânio amorfos. Imagens de MEV e AFM indicaram a presença de poros ou furos em filme depositado com atmosfera rica em hidrogênio e pouco ou nenhuma presença de furos quando o filme foi depositado em atmosfera com maiores quantidades de nitrogênio.

\section{AGRADECIMENTOS}

Agradecemos ao Dr V.P. Nascimento em relação às primeiras orientações sobre o uso de software Wingixa. Agradecemos também a CNPQ, CAPES, FAPES e FINEP e Ifes que contribuíram financeiramente para a realização deste trabalho.

\section{BIBLIOGRAFIA}

[1] KOCH, H., FRIEDRICH, L.J., HINKEL, V., et al., "Hollow Cathode Discharge Sputtering Device for Uniform Large Area Thin Film Deposition”, J. Vac. Sci. Technol. A, v.9, n.4, pp. 2374-2377, 1991.

[2] TARNIOWY, A., MANIA, R., REKAS, M., et al., "The effect of thermal treatment on the structure, optical and electrical properties of amorphous titanium nitride thin films", Thin Solid Films, vol. 311, n.1, pp. 93-100, 1997.

[3] PURUSHOTAM, K.P., WARD, L.P., BRACK, N., et al., "Tribological studies of Zr-implanted PVD TiN coatings deposited on stainless steel substrates", Wear, v.254, pp. 589-596, 2003.

[4] ANNUNZIATA, M., OLIVA, A., BASILE, M.A., et al., "The effects of titanium nitride-coating on the topographic and biological features of TPS implant surfaces”, Journal of Dentistry, v.39, pp. 720-728, 2011.

[5] SCHALDACH, M., "Eletrodo com deposição crepitante TiN para melhor desempenho na estimulação cardíaca”, Rev. Bras. Marcapasso e Arritmia, v.3, n.3, pp.106-11, 1990.

[6] ZHENG, P., ZHAO, G., ZHANG, T., et al., "Study of titanium nitride for low-e coating application", Chinese Science Bulletin, v.52, n.13, pp.1860-1863, 2007.

[7] YUSTE, M., GALINDO, R.E., CARVALHO, S., et al, "Improving the visible transmittance of low-e titanium nitride based coatings for solar thermal applications”, Applied Surface Science, v. 258, Issue 5, pp. 1784-1788, dec. 2011.

[8] DAULDT, N.F., BARBOSA, J.C.P, BRAZ,D.C., et al., “ TiN thin film deposition by cathodic cage discharge: effect of cage configuration and active species", Journal of Physics: Conference Series, v. 406, pp. 12021-12027, 2012.

[9] YAZDANI, A., SOLTANIEH, M., AGHAJANI, H., et al., 'A new method for deposition of nano sized titanium nitride on steels", Vacuum, v. 86, pp.131-139,2011.

[10] DAULDT, N.F., BARBOSA, J.C.P, MACÊDO, M.O.C., et al., "Estudo da viabilidade da técnica de plasma em descarga de gaiola catódica para obtenção de filmes de TiN para revestimentos biocompatíveis", Revista Brasileira de Inovação e Tecnologia em Saúde, v.2, n.2, 2012. 
[11] DAUDT, N.D., BARBOSA, J. C. P., MACÊDO, M.O.C, ALVES JR., C. "Deposição de filmes de TiN por gaiola catódica em atmosfera de plasma de $\mathrm{Ar}-\mathrm{N}_{2}-\mathrm{H}_{2}$.", Revista Brasileira de Aplicações de Vácuo, v. 30 , n.1-2, pp. 36-40, 2011.

[12] VASU, K., KRISHNA, M.G., PADMANABHAN, K.A., "Conductive-atomic force microscopy study of local electron transport in nanostructured titanium nitride thin films", Thin Solid Films, v. 519, n.22, pp. 7702-7706, 2011. 